\title{
A NEW SPECIES OF PSEUDOPARACLIUS (DIPTERA: DOLICHOPODIDAE) FROM SOUTH AFRICA
}

\author{
Igor Ya. Grichanov \\ All-Russian Institute of Plant Protection, Russia \\ e-mail: grichanov@mail.ru
}

Received: 04.02.2020. Revised: 19.02.2020. Accepted: 25.02.2020.

\begin{abstract}
The genus Pseudoparaclius is endemic to the Afrotropical Region. Pseudoparaclius manningi sp.n. is described from the Ukhahlamba Drakensberg Park in KwaZulu-Natal Province of the Republic of South Africa; a key to the nine known southern African species of Pseudoparaclius is provided. P. manningi male differs from other species of the genus in mostly brown-black femora, unmodified podomeres without remarkable setae, strongly elongated clypeus, and morphology of hypopygium. New data on the type species of the genus, $P$. brincki, are also given.
\end{abstract}

Key words: Afrotropical, Dolichopodinae, KwaZulu-Natal, Maloti-Drakensberg Transfrontier Conservation Area, Pseudoparaclius manningi, taxonomic key

\section{Introduction}

In contrast to neighbouring countries, the South African fauna of long-legged flies (Dolichopodidae) is relatively well studied, but is expected to reach at least 250 species with its currently known 190 species (Grichanov, 2018, 2019a,b). The results of the Dolichopodidae investigation support the pattern of a high degree of endemism with many species and some genera being confined only to this territory.

The genus Pseudoparaclius Grichanov, 2006 has been created for 14 species of Paracleius Bigot, 1859 (now synonym to Pelastoneurus Loew, 1861) distributed in Afrotropical countries from Ivory Coast in the West to Kenya in the East and the Republic of South Africa in the South of the continent (Grichanov, 2004, 2006). Subsequently Kaae et al. (2015) described P. udzungwa Kaae, Grichanov et Pape, 2015, from Tanzania, related the species to the Tanzanian endemic P. sanjensis (Grichanov, 2004), and compiled a key to the known species of the genus including two undescribed species from Ivory Coast and Madagascar. The authors suggested that the genus has a much wider distribution, occurring in the Orient, reaching Japan and Australia. New records or illustrations for some species from South Africa have been published by Grichanov et al. (2011a,b) and Grichanov (2011).

In this paper a new species of Pseudoparaclius from South Africa is described, and an identification key to the nine known southern African species is firstly provided. In addition, new data on the type species of the genus, P. brincki (Vanschuytbroeck, 1960), including new records and first colour photos are given. Only two southern African species occur outside this territory. In all, eight species are recorded from South Africa, and one species from Zimbabwe.

\section{Material and Methods}

A new Pseudoparaclius species has been collected from the Mkhomazi Wilderness Area, which refers to a large section of the southern parts of Ukhahlamba Drakensberg Park in KwaZulu-Natal, South Africa. The latter and the Sehlabathebe National Park in the Kingdom of Lesotho were linked together on 11 June 2001 as Maloti-Drakensberg Park or Maloti-Drakensberg Transfrontier Conservation Area. The diversity of habitats on this site protects a high level of endemic and globally important plants and animals (see UNESCO World Heritage Centre, 2020 for further reading).

A new Pseudoparaclius species discovered is photographed with a ZEISS Discovery V-12 stereo microscope and an AxioCam MRc5 camera. Genitalia preparations have been photographed with a ZEISS Axiostar stereo microscope and an AxioCam ICc3 camera. Morphological terminology and abbreviations follow Cumming \& Wood (2017) and Grichanov \& Brooks (2017). The body length is measured from the base of the antenna to the posterior tip of epandrium. The wing length is measured from the base to the wing apex. In citations of labels below the lines as they appear in each label are separated by a slash «/» and data of different labels are separated by a double slash «//».The types of the new species and other material are housed at the Natal Museum, Pietermaritzburg, KwaZulu-Natal, South Africa (NMSA).

\section{Genus Pseudoparaclius Grichanov}

Pseudoparaclius Grichanov, 2006: 29. Type-species, Pelastoneurus brincki Vanschuytbroeck, 1960, by original designation (Fig. 1). 

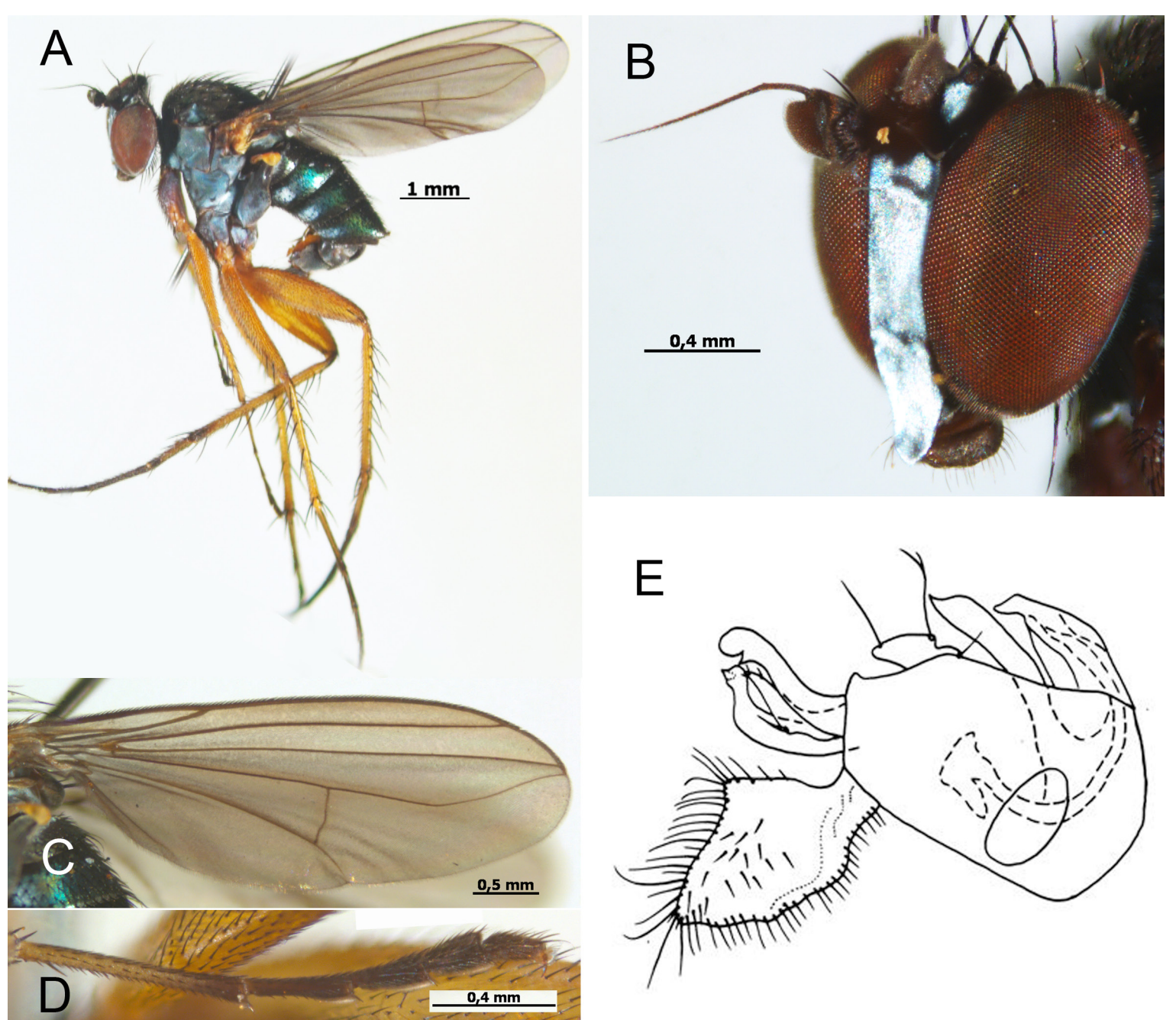

Fig. 1. Pseudoparaclius brincki (Vanschuytbroeck, 1960), male. A - habitus; B - head; C - wing; D - fore tarsus; E - hypopygium, left lateral view. (Fig. 1E, according to Grichanov, 2004).

Remarks. See Grichanov (2006) and Grichanov \& Brooks (2017) for diagnosis of the genus Pseudoparaclius. Males differ from females in some male secondary sexual characters on legs (MSSC). Females of closely related species are probably indistinguishable.

\section{Description of the new species}

Pseudoparaclius manningi Grichanov sp.n. (Fig. 2, Fig. 3).

Material. Holotype: $\delta^{\lambda}$ labelled: «South Africa:

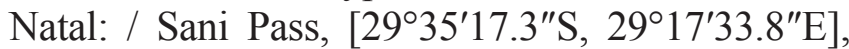
$2000 \mathrm{~m}, / 14.12 .1984$, rocks in mountain stream, / J. Manning»; // «Holotype, Pseudoparaclius / manningi Grichanov [red label]». Paratypes: $3 \hat{\jmath}, 4+$ same data and depository as holotype. One paratype has its male terminalia dissected and stored in glycerin in a microvial pinned with the source specimen. Types are deposited in the collection of NMSA.

Male (Fig. 2, Fig. 3). Body length 4.1-4.5 $\mathrm{mm}$, wing length $4.2-4.9 \mathrm{~mm}$, greatest wing width $1.6 \mathrm{~mm}$.
Head. Frons and face black, with dense silvery-white microtomentum (Fig. 2B). Two long black ocellar setae. Postocular setae black. Compound eyes, with short ommatrichia, face under antennae nearly 2 times as wide as postpedicel and nearly parallel-sided, glabrous, with slightly bulging and strongly projecting downward clypeus; clypeus narrowing downward, with rounded apex; width of face under antennae to length of face between antennae and clypeus to length of clypeus $=0.39 \mathrm{~mm}, 0.47 \mathrm{~mm}, 0.57 \mathrm{~mm}$. Antenna (Fig. 2C) black, scape with setae on dorsal surface and short inner acute projection. Pedicel short and rather compressed, convex anteriad with one strong dorsal seta and ring of short setae. Postpedicel rounded, convex anteriad, slightly longer than high (5/4), with microtrichia; aristalike stylus with short hairs, positioned near middle of dorsal side of postpedicel. Length of scape to pedicel to postpedicel to stylus $\left(1^{\text {st }}\right.$ and $2^{\text {nd }}$ segments) $=0.17 \mathrm{~mm}, 0.15 \mathrm{~mm}, 0.26 \mathrm{~mm}, 0.21 \mathrm{~mm}$, $0.66 \mathrm{~mm}$. Palpus and proboscis short, black. 


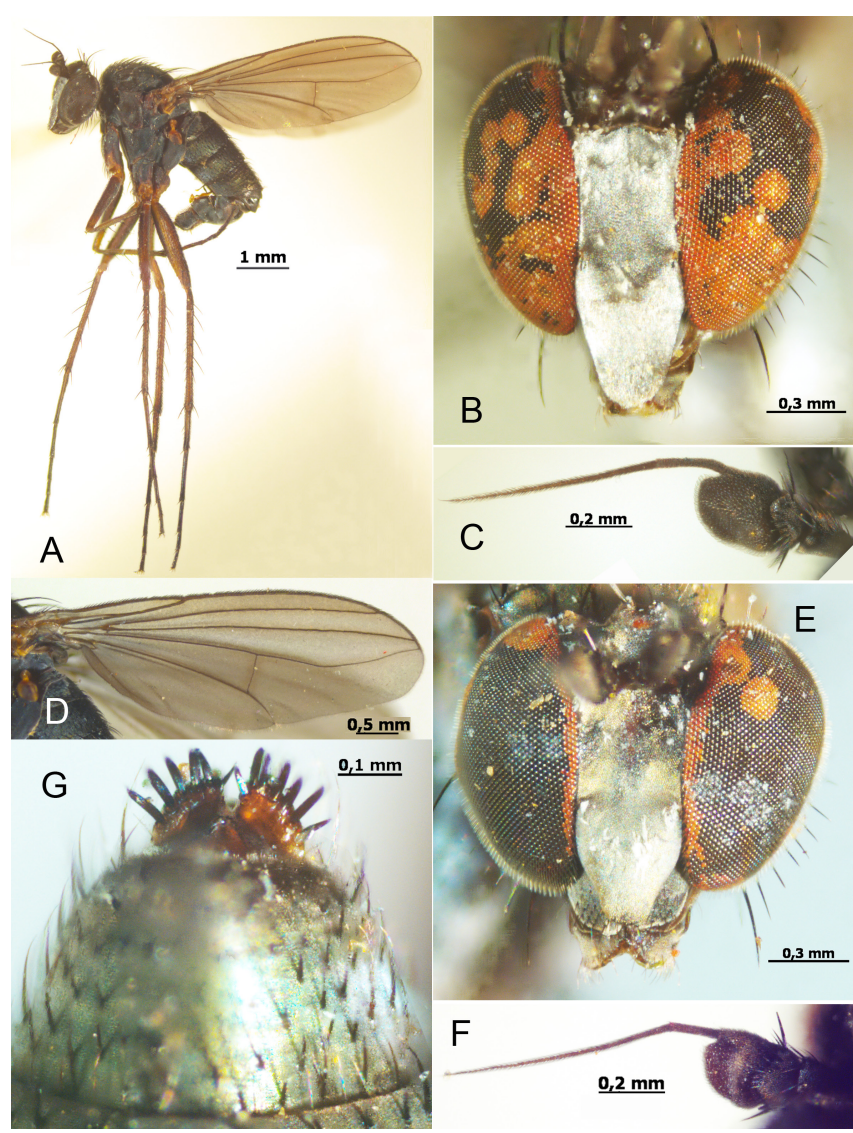

Fig. 2. Pseudoparaclius manningi Grichanov, sp.n., male (AD) and female (E-G). A - habitus; B, E - head; C, F - antenna; $\mathrm{D}$ - wing; $\mathrm{G}$ - oviscapt, dorsal view.

Thorax mostly bluish-greenish black and metallic shiny, with whitish pollinose pleura, mesonotum with strong black dorsal setae; 6 dorsocentral setae decreasing in size anteriorly; 2 rows of acrostichals. Proepisternum with one strong black seta. Anepisternum, katepisternum and meron without setae; metepimeron with small patch of light setae along lower part of posterior margin. Postpronotal lobe with 1 strong erect black seta. Scutellum with 2 strong setae and 2 short lateral hair-like setae.

Legs. Coxae mostly black but with orange brown colour at apex; femora mostly black, with black setae, but fore and mid femora orangebrown at apex, hind femur with orange lateral stripe on both sides; tibiae orange with blackish apex. Fore femur with posteroventral preapical seta. Fore tibia with 3 anterodorsal, 2 posterodorsal and 2 unequal apicodorsal setae. Tarsomere 1 of fore and mid tarsi mostly orange but blackish at apical part, tarsomeres 2-5 black; fore tarsomeres practically simple, equal in width, tarsomere 2 at apex and tarsomeres 3-4 with ventral pad of microscopic erect hairs (MSSC). Length of fore femur to tibia to tarsus (tarsomer- es from 1-5) $=1.34 \mathrm{~mm}, 1.34 \mathrm{~mm}, 0.72 \mathrm{~mm}$, $0.33 \mathrm{~mm}, 0.24 \mathrm{~mm}, 0.18 \mathrm{~mm}, 0.21 \mathrm{~mm}$. Mid femur with 1-2 anterior preapical seta. Mid tibia with 3-4 anterodorsal, 3-4 posterodorsal, 2 ventral at $1 / 3$ and $2 / 3$ and 5 apical setae. Length of mid femur to tibia to tarsus (tarsomeres 1-5) $=$ $1.7 \mathrm{~mm}, 1.89 \mathrm{~mm}, 1.17 \mathrm{~mm}, 0.62 \mathrm{~mm}, 0.46 \mathrm{~mm}$, $0.23 \mathrm{~mm}, 0.3 \mathrm{~mm}$. Hind femur with 1 anterior preapical seta. Hind tibia with 3-4 anterodorsal, 3-5 posterodorsal, 3 apical and about 6 fine ventral setae. Hind tarsomere 1 with orange ring at base, with 1 short basoventral seta. Length of hind femur to tibia to tarsus (tarsomeres $1-5)=$ $1.73 \mathrm{~mm}, 2.2 \mathrm{~mm}, 0.76 \mathrm{~mm}, 0.98 \mathrm{~mm}, 0.64 \mathrm{~mm}$, $0.38 \mathrm{~mm}, 0.27 \mathrm{~mm}$.
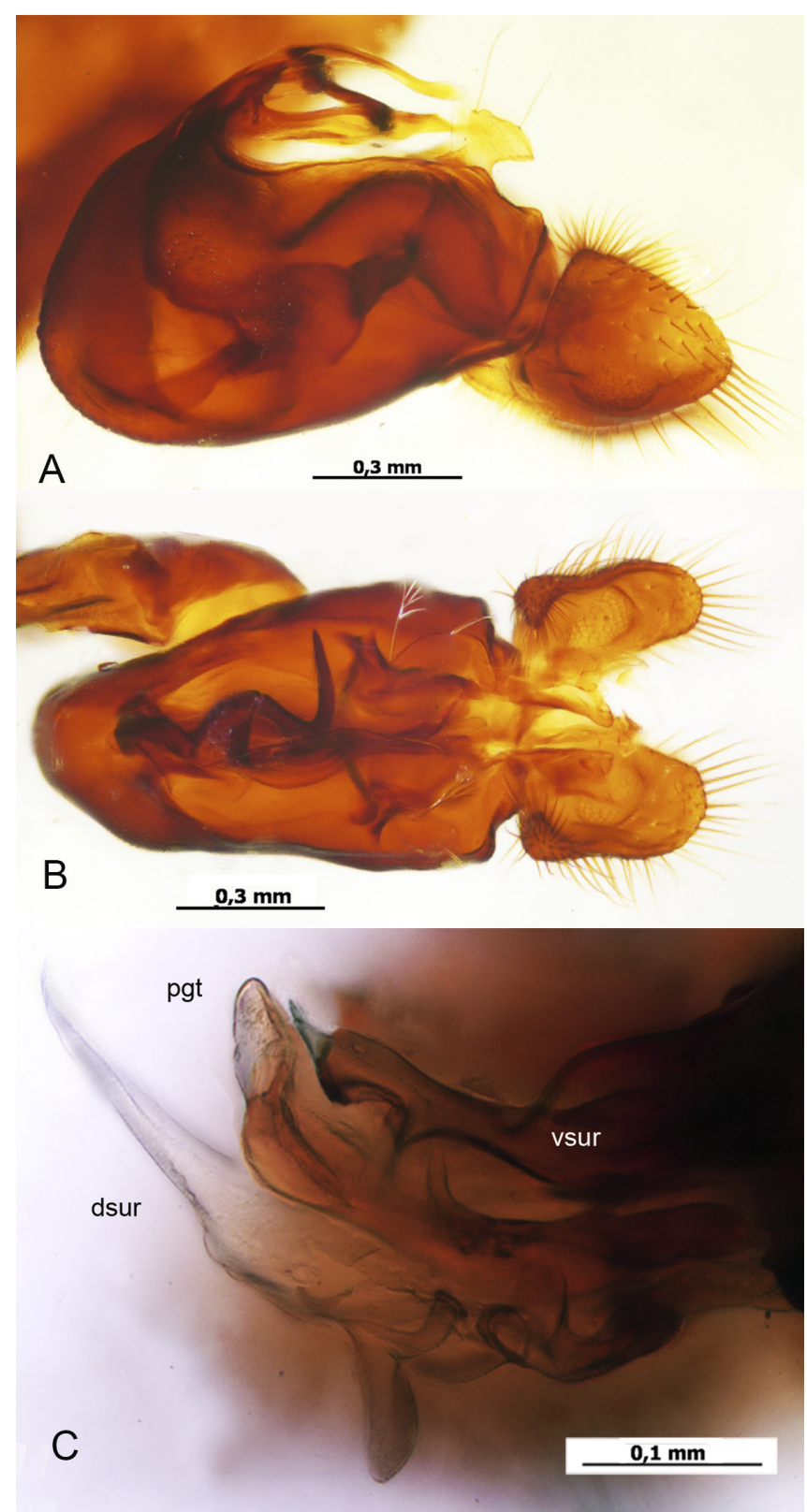

Fig. 3. Pseudoparaclius manningi Grichanov, sp.n., male genitalia. A - hypopygium, right lateral view; B - hypopygium, ventral view; C - postgonite (pgt), ventral (vsur) and dorsal (dsur) lobes of surstylus, lateral view. 
Wing (Fig. 2D) greyish with slight brownish anterior tinge extending from $\mathrm{R}_{1}$ to $\mathrm{R}_{4+5}$. Veins dark brown. Costa simple. $\mathrm{M}_{1+2}$ convergent towards $\mathrm{R}_{4+5}$ just before middle of distal part and joining Costa just before wing apex; ratio of part of Costa between $R_{2+3}$ and $R_{4+5}$ to this between $\mathrm{R}_{4+5}$ and $\mathrm{M}_{1+2}$, $=4.4$. Crossvein dm-m straight, forming right angle with both longitudinal veins; ratio of $\mathrm{dm}-\mathrm{m}$ to $\mathrm{M}_{4}=1$. $\mathrm{M}_{4}$ not reaching wing margin. Posterior wing margin almost evenly convex. Anal vein distinct; anal lobe pronounced; anal angle obtuse. Lower calypter yellow with black setae. Halter orange yellow with brown knob.

Abdomen bluish-black and concolourous with thorax but with whitish microtomentum laterally. Epandrium black (Fig. 3A,B). Distoventral epandrial lobe large, broader at apex than at base, bearing three dorsal setae at base, mid-length and tip respectively, 2 apical setae distinctly branched. Hypandrium with pair of curved pointed lateral lobes arising from extreme base; one lobe flat, wide, gently curved, with pair of subapical denticles; second lobe strongly sclerotised, S-shaped, thin, with short process at base (Fig. 3B). Phallus thin, almost straight. Postgonite as wide as and as long as ventral lobe of surstylus, curved ventrally, angular at apex. Surstylus slightly curved, with 2 narrow lobes; ventral lobe rounded at apex, with apical spine and subapical excavation; dorsal lobe of surstylus long, broad basally, pointed at apex. Cercus black, rounded-triangular, about as long as wide, $0.46 \mathrm{x}$ as long as epandrium, with short, black marginal setae and with microtrichia on inner side (Fig. 3A,B).

Female (Fig. 2E,F,G). Similar to male except lacking MSSC; face grey-white (Fig. 2E); clypeus less projecting downward than that in male; width of face under antennae to length of face between antennae and clypeus to length of clypeus $=0.39 \mathrm{~mm}, 0.43 \mathrm{~mm}, 0.46 \mathrm{~mm}$; postpedicel as long as high at base (23/21). Length of scape to pedicel to postpedicel to stylus $\left(1^{\text {st }}\right.$ and $2^{\text {nd }}$ segments $)=0.17 \mathrm{~mm}, 0.12$ $\mathrm{mm}, 0.23 \mathrm{~mm}, 0.16 \mathrm{~mm}, 0.71 \mathrm{~mm}$ (Fig. 2F). Oviscapt with each hemitergite with 7 thick spines (Fig. 2G).

\section{Differential diagnosis}

The male of the new species differs from other species of the genus in mostly brown-black femora, unmodified podomeres without remarkable setae, strongly elongated clypeus and morphology of hypopygium (see key below). Pseudoparaclius zogualensis (Grichanov, 2004) male described from Ivory Coast also has simple legs, but with yellow femora; narrow face and small clypeus, not reaching lower margin of eyes; cercus nearly 2 times longer than high, with narrow distal apex (see Grichanov, 2004, Fig. 129).

Distribution. Afrotropical - South Africa.

Etymology. The species is named after J. Manning, who collected the type series.

Biology. According to labels under the type specimens, imagos inhabit rocks in mountain streams. This station corresponds to the known habitats of some other species of the genus, i.e. temperate forests in the mountains of South Africa and tropical woodlands in the mountains of East Africa (see Grichanov, 2004; Kaae et al., 2015).

Specimens of $\boldsymbol{P}$. brincki examined (Fig. 1). South Africa: 2へ, 2q, «Michell's Pass, / Ceres

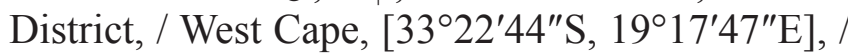
6.10.1959, / B. \& P. Stuckenberg» (NMSA); $1{ }^{\lambda}$, 1ㅇ, «Otterford Forestry Reserve, / Hankey Area, /

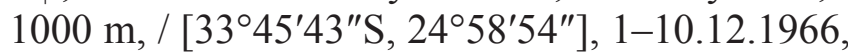
3325CC, / B. \& P. Stuckenberg» (NMSA).

\section{Key to the species of Pseudoparaclius (males) from South Africa and Zimbabwe}

This key is built on Kaae et al. (2015) but has scattered modifications based on material examined for the present study.

1. Legs including fore tarsus and mid femur simple, without modified segments or groups of remarkable hairs; cercus subtriangular, as long as high; body $4.1-4.5 \mathrm{~mm}$ (South Africa; Fig. 2, Fig. 3) ... P. manningi Grichanov, sp.n. - Some segments of fore tarsus distinctly thickened or flattened laterally; sometimes mid femur with remarkable ventral hairs or setae

2. All femora mostly black except pale apices, fore femur sometimes orange-brown ........................................... 3

- All femora yellow, sometimes blackish dorsally, rarely hind femur mostly black ............................................. 6

3. Mid femur with ventral comb of flattened setae in middle, at least as long as greatest diameter of femur; cercus semi-lunular, rounded at apex; body $3.5 \mathrm{~mm}$ (Zimbabwe; see Parent, 1934, Fig. 43, Fig. 44, Fig. 45) ......... P. atricornis (Parent, 1934) - Mid femur without a midventral comb, with anteroventral pile of setulae, almost half as long as greatest diameter of femur, or with sparse setae 
4. Mid femur with short anteroventral pile only at base; body $4.5 \mathrm{~mm}$ (Kenya, Tanzania, South Africa; see Grichanov, 2004, Fig. 105, Fig. 106) P. ngarukaensis (Vanschuytbroeck, 1964)

- Mid femur with anteroventral pile along proximal 1/2-2/3

5. Hind tibia entirely yellow; hind tarsomere 1 yellow with black apex; cercus subtriangular, angular ventrally, with long, thin dorsobasal process having short, undulated setae at apex; body 4.8-5.0 mm (South Africa; see Grichanov, 2004, Fig. 71; Grichanov, 2011, Fig. 91, Fig. 92, Fig. 93)

P. funditor (Curran, 1926)

- Hind tibia yellow with blackish apex; hind tarsomere 1 entirely black; cercus fabiform, rounded ventrally, without dorsobasal process; body 4.0-4.5 mm (South Africa; see Grichanov, 2011, Fig. 90) ........ P. afer (Curran, 1926) 6. Fore tarsomere 1 thickened in basal 2/3; hind tarsus black; all femora blackish dorsally; mid femur with ventral comb of flattened setae in middle, as long as greatest diameter of femur; cercus semilunular, rounded at apex; body $3.5 \mathrm{~mm}$ (Zimbabwe; see Parent, 1934, Fig. 43, Fig. 44, Fig. 45) P. atricornis (Parent, 1934) - Fore tarsomere 1 usually not thickened; hind tarsus usually at least partly yellow; other attributes various ........ 7 7. Hind tarsomere 1 entirely black; wing blackish along longitudinal veins and at dm-m; 3rd and 4th segments slightly but distinctly widened and flattened laterally; cercus small, blackish; body $4.0 \mathrm{~mm}$ (South Africa) P. obscoenus (Wiedemann, 1830)

- Hind tarsomere 1 mostly yellow; wing evenly greyish, brownish along costa; cercus variable in shape and colour ............ 8 8. Fore tarsomeres $4-5$ slightly compressed and laterally flattened; tarsomere 3 thickened at apex or slightly widened and flattened; body 4.2-4.4 mm (South Africa; Fig. 1) ...

P. brincki (Vanschuytbroeck, 1960) - At least fore tarsomeres 4-5 strongly laterally compressed; male cercus with short, dark cilia, half as long as cercus width; body about $4 \mathrm{~mm}$ (Democratic Republic of the Congo, South Africa, Tanzania, Uganda; see Grichanov, 2004, Fig. 89, Fig. 90) ..... P. maranguensis (Vanschuytbroeck, 1964)

\section{Acknowledgements}

The author is sincerely grateful to Mike Mostovsky (Steinhardt Museum of Natural History, Tel Aviv, Israel) for providing the specimens studied in this research. The work was funded by RFBR and NSFC according to the research project No. 20-54-53005. The comparative analysis of morphological characters and the preparation of illustrations were performed within the Program for Basic Scientific Research of the Government of the Russian Federation, project No. 0665-2020-0014. Two anonymous reviewers kindly commented on earlier drafts of the manuscript.

\section{References}

Cumming J.M., Wood D.M. 2017. 3. Adult morphology and terminology. In: A.H. Kirk-Spriggs, B.J. Sinclair (Eds.): Manual of Afrotropical Diptera. Vol. 1. Introductory chapters and keys to Diptera families. Suricata 4. Pretoria: SANBI Graphics \& Editing. P. 89-134.

Grichanov I.Ya. 2004. Review of Afrotropical Dolichopodinae (Diptera: Dolichopodidae). St. Petersburg: VIZR. 244 p. (Plant Protection News Supplements)

Grichanov I.Ya. 2006. New genera and combinations for Afrotropical Dolichopodinae (Dolichopodidae, Diptera). International Journal of Dipterological Research 17(1): 23-34.

Grichanov I.Ya. 2011. An illustrated synopsis and keys to Afrotropical genera of the epifamily Dolichopodoidae (Diptera: Empidoidea). Priamus Supplement 24: 1-98.

Grichanov I.Ya. 2018. An annotated catalogue of Afrotropical Dolichopodoidae (Diptera). St. Petersburg: VIZR. 152 p. (Plant Protection News Supplements 25). DOI: 10.5281/zenodo. 1187006
Grichanov I.Ya. 2019a. New Afrotropical species of Tenuopus Curran, 1924 (Diptera: Dolichopodidae). Russian Entomological Journal 28(4): 460-463. DOI: 10.15298/rusentj.28.4.15

Grichanov I.Ya. 2019b. Discovery of Udzungwomyia Grichanov in South Africa and definition of a new tribe Udzungwomyiini (Diptera: Dolichopodidae). Israel Journal of Entomology 49(2): 267-275. DOI: 10.5281/zenodo.3562003

Grichanov I.Ya., Brooks S.E. 2017. 56. Dolichopodidae (long-legged dance flies). In: A.H. Kirk-Spriggs, B.J. Sinclair (Eds.): Manual of Afrotropical Diptera, Vol. 2. Nematocerous Diptera and Lower Brachycera. Suricata 5. Pretoria: SANBI Graphics \& Editing. P. 1265-1320.

Grichanov I.Ya., Mostovski M.B., Muller B. 2011a. New records of Afrotropical Dolichopodidae (Diptera) from the collection of Natal Museum (1). International Journal of Dipterological Research 22(1): 3-9.

Grichanov I.Ya., Mostovski M.B., Muller B. 2011b. New records of Afrotropical Dolichopodidae (Diptera) from the collection of Natal Museum (2). International Journal of Dipterological Research 22(2): 81-98.

Kaae M.E., Grichanov I., Pape T. 2015. A new species of Pseudoparaclius Grichanov (Diptera: Dolichopodidae) from Udzungwa Mountains National Park, Tanzania, and a key to Afrotropical species. Zootaxa 4018(1): 137-145.

Parent O. 1934. Additions à la faune éthiopienne (diptères: dolichopodides). Bulletin de la Société Royale Entomologique d'Égypte 18: 112-138.

UNESCO World Heritage Centre. 2020. Maloti-Drakensberg Park. Paris, France. Available from: http://whc.unesco. org/en/list/985 
НОВЫЙ ВИД РОДА PSEUDOPARACLIUS (DOLICHOPODIDAE, DIPTERA) ИЗ ЮЖНОЙ АФРИКИ

\section{И. Я. Гричанов}

Всероссийский институт защиты растений, Россия
e-mail: grichanov@mail.ru

Род Pseudoparaclius является эндемиком Афротропической области. Описан новый вид Pseudoparaclius manningi sp.n. из национального парка Укхахламба-Дракенсберг в провинции Квазулу-Натал ЮжноАфриканской Республики. Составлен ключ для определения девяти южноафриканских видов Pseudoparaclius. Самец P. manningi отличается от других видов рода в основном коричнево-черными бедрами, простыми члениками лапок и простыми щетинками на ногах, удлиненным наличником лица и морфологией гипопигия. Также приведены новые данные о типовом виде рода $P$. brincki.

Ключевые слова: Dolichopodinae, Pseudoparaclius manningi, Афротропика, Квазулу Натал, ключ, Пограничная природоохранная зона Малоти-Дракенсберг 